\title{
Did Emanuel Swedenborg Have Near-Death Experiences? Envisioning a Developmental Account of NDEs
}

\author{
Simon R. Jones, M.A. \\ Charles Fernyhough, Ph.D. \\ Durham University, UK
}

\begin{abstract}
The causes of Emanuel Swedenborg's (1688-1772) voices and visions remain unclear. It has recently been argued that post-hoc diagnoses of schizophrenia and epilepsy are not congruent with Swedenborg's actual experiences. In this article we examine the phenomenological commonalities between Swedenborg's experiences and near-death experiences (NDEs). Using the Near-Death Experience Scale (Greyson, 1985), we show that Swedenborg's experiences meet accepted criteria to be classified as NDEs. However, despite significant evidence for such commonalities, Swedenborg's experiences also show a number of points of divergence from NDEs. After reviewing the evidence for a potential role of hypoxia in generating NDEs, we hypothesize that a proximal cause of Swedenborg's experiences was his tendency to hypoventilate. Further, we argue that a distal cause of Swedenborg's experiences was neural changes induced by his lifetime of unusual respiration, in conjunction with a predisposition to temporal lobe seizures. We conclude by proposing a number of empirically testable hypotheses emerging from our arguments, centered around a developmental approach to NDEs.
\end{abstract}

KEY WORDS: development; hallucinations; hypoxia; near-death experience; Emanuel Swedenborg.

Simon R. Jones, M.A., is a Doctoral Candidate in Psychology at Durham University, United Kingdom, where Charles Fernyhough, Ph.D., is a part-time Senior Lecturer in Psychology. The authors wish to thank Profs. Janice Holden and Bruce Greyson for their helpful suggestions during the finalization of this article. Reprint requests should be addressed to Simon R. Jones at the Department of Psychology, Durham University, South Road, Durham DH1 3LE, United Kingdom; e-mail: s.r.jones@durham.ac.uk. 
Emanuel Swedenborg's (1688-1772) experiences were, in the words of William James (1902/1960), "the palmary one[s] of audita et visa, serving as a basis of religious revelation" (p. 460). Experienced through a range of sensory modalities, reflected in his memorable phrase "I have seen, I have heard, I have felt" (1749-1756/1872, n68), Swedenborg's voices and visions are detailed in the records he kept in a range of works including his Spiritual Diary (1746-1765/1883), The Word of the Old Testament Explained (1746-1747/1928), Arcana Coelestia (1749-1756/1872), Life on Other Planets (1758/2006), Heaven and Hell (1758/1931), and True Christian Religion (1771/1883). He wrote these works in short passages that he numbered; thus, in this article, we will follow the custom of citing direct quotes from his work with reference to " $n$ " for passage number rather than " $p$ " for page number.

The form and content of Swedenborg's experiences evolved over time (Toksvig, 1948), exhibiting a significantly different character pre- and post-1744. In the eight years before 1744, Swedenborg's experiences included dreams, "visions when my eyes were closed," "fiery lights," and hearing "speech in morning time" (1746-1765/1883, n2951). Swedenborg later noted that had the nature of these events not changed post-1744, then he could "have fallen into the opinion (that these) things were phantasies" (1746-1765/1883, n2951). However, following two separate occasions in April 1744 and April 1745 in which Swedenborg experienced seeing Jesus and God respectively, both of whom spoke to him during nighttime visions, the nature of his experiences changed. During these events, Swedenborg experienced what he later described as the opening of his "interior sight" (1749$1756 / 1872$, n1619), allowing him to see and hear "things of another life, which cannot possibly be made visible to the bodily sight" (1749$1756 / 1872, \mathrm{n} 1619$ ). Swedenborg was henceforth able to enter into a 'spiritual world' on a daily basis and to engage in detailed conversations with the beings he encountered there, which he understood variously as spirits, angels, and demons (for further descriptions, see Benz, 2002; Jones \& Fernyhough, 2008; Toksvig, 1948). In a typical example of his later experiences (Benz, 2002) Swedenborg reported the following. While "engaged in meditation upon the creation of the universe," he recorded that an angel "above me on the right" noticed him and, "descended, and invited me up" into a spiritual world (1771/1883, n76). Swedenborg claimed that he was then conducted to the palace of a prince where there ensued a long 
discussion with its occupants, after which "the angel, who had introduced me, accompanied me to the house where he found me, and from thence re-ascended to his own society" (n76).

Swedenborg (1758/1931) developed a detailed topography of the spiritual world he encountered. From his experiences he described how, after death, an individual's spirit went into a spiritual realm, an intermediate state between heaven and hell. This world appeared "like a valley between mountains and rocks, with here and there windings and elevations" (n428). It was in this intermediate zone that newly deceased individuals were thought to meet their friends and family. The purpose of this spiritual realm was for individuals to reveal their true identities, after which they would either descend to hell or ascend to heaven, through "gates and doors" (n429).

\section{Understanding and Explaining Swedenborg's Experiences}

For over two centuries, investigators have scrutinized Swedenborg's experiences. From within medicine, psychiatrists have proposed that Swedenborg suffered variously from monomania (Maudsley, 1869), schizophrenia (Jaspers, 1923/1962), epilepsy (Foote-Smith \& Smith, 1996), and non-epileptic partial complex seizures associated with vascular disease (Bradford, 1999). We have recently argued (Jones \& Fernyhough, 2008) that the phenomenology of Swedenborg's experiences does not fit with any of these diagnoses and that he should instead be understood as experiencing hallucinations without mental disorder. Such an approach stems from research showing that otherwise healthy individuals may experience hallucinations in the absence of the social dysfunction or distress associated with clinical psychosis and that such experiences exist on a continuum stretching into the normal population (de Boismont, 1860; Johns \& van Os, 2001; Posey \& Losch, 1983; Tien, 1991).

Notwithstanding our call for Swedenborg's experiences to be reinterpreted within discourses outside medical psychiatry (Jones \& Fernyhough, 2008), the physiological and biological causes of his voices and visions remain to be explained. In this article we address the likely causes of Swedenborg's experiences, employing the distinction between likely proximal and distal causes. Whereas a proximal cause is the link in a causal chain that immediately precedes an event, 
a distal cause is a link in the causal chain that precedes the proximal cause (Jackson \& Coltheart, 2001). For example, whereas the immediate, proximal cause of a stomach pain may be an acidic meal, the more removed, distal cause may be stress over a period of years causing a proneness to stomach ulcers, possibly with a genetic predisposition to develop such ulcers.

In contrast to the finding that Swedenborg's experiences have only limited phenomenological parallels with the hallucinations of schizophrenia and epilepsy (Jones \& Fernyhough, 2008), both Raymond Moody (1975) and Leon Rhodes $(1982,1996)$ have argued that a number of phenomenological commonalities exist between Swedenborg's experiences and those reported by individuals during near-death experiences.

Across cultures that include European, Middle Eastern, African, Indian, East Asian, Pacific, and Native American, the dying have reported anomalous experiences (Greyson, 2006). However, it was not until 1975 that Moody brought such experiences together under the heading of "near-death experiences" (NDEs; p. 13). Moody and Paul Perry (1988) subsequently defined NDEs as "profound spiritual events that happen, uninvited, to some individuals at the point of death" (p. 11). After reviewing 150 cases of NDEs, Moody was able to delineate 15 common aspects of the experience. These included inexpressibility, feelings of peace and quiet, unusual auditory experiences, seeing a dark tunnel, meeting other spiritual beings, a life review, and coming back into the body. These features may occur whatever the cause of the NDE, be it cardiac arrest, accidents, or suicide (Greyson, 2006). Furthermore, culturally contingent social representations of the afterlife, and hence individuals' expectations of it, do not appear to influence the form or content of the NDE itself (Athappilly, Greyson, \& Stevenson 2006).

In the present paper, we set out to examine three questions. First, to what extent did Swedenborg's experiences share commonalities with NDEs reported today? Second, if significant parallels are found, what common mechanisms may underlie Swedenborg's experiences and NDEs? Finally, how can Swedenborg's experiences inform ongoing efforts to study, conceptualize, and offer theoretical explanations for NDEs?

\section{Were Swedenborg's Experiences like NDEs?}

Moody (1975) was first to propose parallels between Swedenborg's experiences and NDEs. He claimed that Swedenborg's day-to-day 
voices and visions, involving leaving the body, speaking with angels, and seeing bright lights, were consistent with many facets of modern day NDEs. However, Moody's aim was not to provide a systematic analysis of Swedenborg's experiences; rather, his interest in the two forms of experience was in supporting his claim for the ahistorical, universal nature of NDEs. Furthermore, as a basis for his claim, Moody consulted only one anthology of Swedenborg's writings.

In later studies, Rhodes $(1982,1996)$ overcame these limitations of Moody's (1975) work by using a far greater range of Swedenborg's works to examine his experiences in the context of NDEs. Rhodes (1982) concluded that "the NDE is closely related to Swedenborg's experiences" (p. 30) and that "on numerous ... occasions [Swedenborg] gives descriptions comparable to those of a person returning from a condition of clinical death" (p. 20). However, Rhodes's work, like Moody's, suffers to some degree from a confirmatory bias. Both authors picked out aspects of the phenomenology of Swedenborg's experiences that coincide with those that near-death experiencers (NDErs) report, yet both sidelined or did not address at all those aspects that differ from what NDErs report. Thus, there is a need for a systematic examination of the extent to which Swedenborg's day-today experiences genuinely paralleled those found in NDEs.

Before we compare and contrast the phenomenology of Swedenborg's experiences with those of NDEs, it is important to note one clear difference that Rhodes (1982) identified. Swedenborg's experiences, occurring as they did on a daily basis, were not associated with obvious traumas resulting in a 'near-death' state. Swedenborg made only one reference to a putative near-death state being associated with one of his experiences, and even in that case it appears unlikely that he was physiologically close to dying. In this instance, Swedenborg (1758/ 1931) reported how "by living experience" ( $\mathrm{n} 448$ ) he once underwent the process of dying, followed by being "raised" ( $n 448$ ) into a spiritual world. Swedenborg described how "I was bought into a state of insensibility as to the bodily senses, and thus nearly into the state of dying persons ... and ... I perceived that the respiration of the body was almost taken away" (n448). This process was followed by "a drawing, and, as it were, a pulling out of the interiors of my mind ... from the body" (n448). Swedenborg then reported encountering angels who communicated their thoughts to him by "looking into my face, for in this manner communication of thoughts is effected in heaven" (n448). This experience has many similarities with the experiences 
NDErs report (Moody, 1975). However, in making their claim for a connection between Swedenborg's experiences and NDEs, Moody and Rhodes were more interested in Swedenborg's day-to-day experiences than in this isolated report of a near-death state. It is to these commonalities that we turn first.

\section{Swedenborg's Experiences and NDEs}

Since Moody's (1975) seminal work in which he identified 15 facets of the NDE, researchers have published a large body of systematic study of NDEs (e.g., Greyson, 2000, 2003, 2006; Parnia \& Fenwick, 2002). In particular, Bruce Greyson (1985) devised a tool, the NearDeath Experience Scale (NDE Scale), to develop accepted criteria for their occurrence. This instrument, which is reliable, valid, and easily administrable, enables researchers and clinicians to differentiate NDEs from organic brain syndromes and non-specific stress responses (Greyson, 1985). Participants' NDEs are rated on the presence of 16 components, each of which can score zero, one, or two points, depending on the extent of their presence. Greyson designated a total score of 7 or higher as signifying the presence of an NDE. Although applying this tool to Swedenborg's writings is necessarily a subjective process, we argue that it may be useful in quantifying the extent of the parallels between Swedenborg's experiences and NDEs. In Table 1, we score the applicability of each item on the NDE Scale to Swedenborg's day-to-day experiences. We discuss the reasons for each of these scores below.

The first four items on the NDE Scale relate to cognitive aspects of the experience. Of these four items, we found items 1,3 , and 4 are not typical of Swedenborg's experiences. Time did not appear to speed up during his visions (item 1), scenes from his own past did not come back to him (item 3), and he did not suddenly seem to understand everything (item 4). Instead, the visions typically appeared to take place in real-time, like a film (Benz, 2002), in which Swedenborg encountered novel beings and situations, rather than events from his past; and, rather than sudden flashes of insight, Swedenborg was gradually shown and told details about the spiritual world through didactic conversations. Thus, a conservative approach would score 0 for Swedenborg on all these items.

However, item 2, 'Were your thoughts speeded up,' does appear to be applicable to Swedenborg. Many people who have experienced NDEs 
Table 1

Ratings of Swedenborg's Experiences on the NDE Scale

\begin{tabular}{|c|c|c|c|}
\hline Component & & Item & Score \\
\hline \multirow[t]{4}{*}{ Cognitive } & 1. & Did time seem to speed up? & 0 \\
\hline & 2. & Were your thoughts speeded up? & 1 \\
\hline & 3. & Did scenes from your past come back to you? & 0 \\
\hline & 4. & $\begin{array}{l}\text { Did you suddenly seem to understand } \\
\text { everything? }\end{array}$ & 0 \\
\hline \multirow[t]{4}{*}{ Affective } & 5. & Did you have a feeling of peace or pleasantness? & 2 \\
\hline & 6. & Did you have a feeling of joy? & 2 \\
\hline & 7. & $\begin{array}{l}\text { Did you feel a sense of harmony or unity with } \\
\text { the universe? }\end{array}$ & 0 \\
\hline & & $\begin{array}{l}\text { Did you see or feel surrounded by a brilliant } \\
\text { light? }\end{array}$ & 2 \\
\hline \multirow[t]{4}{*}{ Paranormal } & 9. & Were your senses more vivid than normal? & 1 \\
\hline & 10. & $\begin{array}{l}\text { Did you seem to be aware of things going on } \\
\text { elsewhere, as if by ESP? }\end{array}$ & 0 \\
\hline & 11. & Did scenes from the future come to you? & 0 \\
\hline & 12. & Did you feel separated from your physical body? & 1 \\
\hline \multirow[t]{4}{*}{ Transcendental } & 13 & $\begin{array}{l}\text { Did you seem to enter some other unearthly } \\
\text { world? }\end{array}$ & 2 \\
\hline & & $\begin{array}{l}\text { Did you seem to encounter a mystical being } \\
\text { or presence? }\end{array}$ & 2 \\
\hline & & Did you see deceased spirits or religious figures? & 2 \\
\hline & 16. & Did you come to a point or border of no return? & 1 \\
\hline Total & & & 16 \\
\hline
\end{tabular}

reported "direct, unimpeded transfer of thoughts takes place." Mitchell Leister (1998) gave the example of an individual who described the communications she received during her NDE as being "instant" and a form of "thought transfer" (p. 239). Swedenborg, too, experienced communication via thought transfer. For example, he claimed, "I have frequently discoursed with spirits ... in their proper tongue, that is, by ideas of thought" (1749-1756/1872, 1639). Signe Toksvig (1948) noted that "Swedenborg despaired of expressing the rapidity of this mode of communication" (p. 265) and that he experienced angels as being able to see "all the branching implications of an idea in all its complexity at one and the same time" (p. 265). Swedenborg often seemed to experience the elevation of his thoughts 
to this "cognitive level" (Benz, 2002, p. 285) during his later visions. We conservatively score these phenomena as 1 on the NDE Scale, being faster than usual thoughts-as opposed to the 2-point NDEScore score of incredibly fast.

The second four items on the NDE Scale address affective components of the experience. The emotion Swedenborg portrayed as associated with his experiences varied between his different works. In works published during his lifetime, such as Arcana Coelestia, Swedenborg's visions can come across as dry, didactic, intellectual experiences, or even "downright monotonous events" (Benz, 2002, p. 272). However, in his posthumously published personal diary (1746-1765/1883), Swedenborg revealed the direct, colorful, and emotional aspects of his experiences (Benz, 2002), and it is clear that his writings designed for public consumption are typically "devoid of their original emotional content" (p. 272).

Items 5 and 6 on the NDE Scale address whether the individual had a feeling of peace, pleasantness, or joy during the experience. Swedenborg (1758/1931) described a number of such experiences, reporting how "the peace of heaven has been perceived by me ... [while] ... elevated and withdrawn from the body" (n284). Swedenborg also reported that it was "frequently, and for a long continuance, granted me by the Lord to perceived the delights of heavenly joy" (1749-1756/1872, n545). Such experiences were an "affection of innumerable delights and joys" (n545). We believe both these items qualify for a score of 2 on the NDE Scale, involving as they did extreme peace or pleasantness and joy.

Item 8, which addresses whether the individual saw or felt surrounded by an 'incredible' light, is also applicable to Swedenborg. First, he claimed that angels and spirits "live in an aura of light" (1749-1756/1872, n1116) and, moreover, in "the highest degree of light" (n1116), to which "the midday light of this world cannot be compared" (n322). Elsewhere he stated that the "the light in heaven is such as to exceed the noon day light of this world in a degree surpassing all belief" ( $\mathrm{n} 1521$ ). He also often reported seeing "a bright flaming light, which ... beamed forth before my eyes" ( 1117 ). On this basis, we concluded Swedenborg qualifies for a score of 2 for this item, involving, as his experiences, did a bright or brilliant light he believed to be clearly of mystical or otherworldly origin.

The only affective component we found not applicable to Swedenborg is item 7 of the NDE Scale that addresses whether the individual 
felt a sense of harmony or unity with the universe. Swedenborg did not seem typically to have undergone a feeling of mystical union with the universe, save for rare experiences (see Toksvig, 1948, p. 299). We hence scored him at zero on this item.

Greyson (1985) classified the third set of items on the NDE Scale as involving paranormal aspects. The first of these, item 9, addresses whether the individual's senses were more vivid than normal. This phenomenon was certainly the case for Swedenborg who noted how he saw "every single object much more vividly than ... similar objects on earth" (1749-1756/1872, n1622). We conservatively gave Swedenborg a score of 1 , more vivid than usual, on this item-as opposed to a score of 2 , which requires senses to be incredibly more vivid than normal.

Items 10 and 11 on the NDE Scale address whether the individual seemed to be aware of things going on elsewhere, as if by ESP, or whether scenes from the future came to them. Although Swedenborg claimed to have had psychic experiences (Toksvig, 1948), these features do not appear to have been typical of his visions themselves. Similarly, the content of the visions was not typically of future events but, rather, focused around didactic discussions (Benz, 2002). We therefore scored him zero on both of these items.

Item 12 on the NDE Scale addresses whether the individual felt separated from one's physical body. Greyson and Ian Stevenson (1980) reported that $75 \%$ of NDEs feature such an out-of-body experience, with the majority occurring within a limited area within a few yards of the body. Swedenborg rarely reported the specifics of his transitions between the material world and the spiritual world. As Ernst Benz (2002) noted, most of Swedenborg's descriptions begin with formulaic lead-ins such as, "Once I saw in the spiritual world ..." or "I looked out into the spiritual world and saw ..." or "I was in the spirit when ...." Swedenborg defined "being in the spirit" as "a state of mind separate from the body" (1771/1883, n157). During this state, which Swedenborg inhabited for a period of decades, he recorded that he was "in the spirit and in the body at one and the same time, and only on some particular occasions out of the body" (n157).

These instances of Swedenborg being out of the body included his putative near-death state described above, in which he recorded that he underwent "a drawing, and, as it were, a pulling out of the interiors of my mind ... from the body" (1758/1931, n448). In another example, he described how "I was once withdrawn from ideas of things material, or of the body ... I perceived material things which are such as are 
worldly and corporeal, as beneath me, and remote" (1749-1756/1872, n1526). Swedenborg expanded on what is presumably the same experience in his personal diary. Here he stated that

there appeared $\ldots$ a lively sparkling of light ... like an adamantine light or the light sparkling from diamonds ... and it withdrew me from corporal ideas; yea, from the body itself. When I was in that light I beheld corporeal things as though beneath me, which I indeed felt, but as though removed from me, and not belonging to me. (1746$1765 / 1883$, n 600)

Elsewhere he also reported the experience of being "elevated into the light, which glittered like the light radiating from diamonds" (17491756/1872, n4413). However, as Swedenborg noted himself, such outof-body experiences were rare.

Despite not often undergoing out-of-body experiences, Swedenborg often referred to returning "home" at the end of a vision, when he left the spiritual state and re-entered his physical body (Benz, 2002). Benz stated that, for Swedenborg, "the experience of being 'outside of oneself' and 'in the spirit' is therefore linked with the specific movements and spatial impressions of leaving and returning to his earthly standpoint" (p. 297). Elsewhere, Swedenborg reported occasions in which angels "descended, and invited me up to them" (1771/ $1883, \mathrm{n76}$ ). Thus, Swedenborg appeared to experience some sense of spatial movement away from the body, although the phenomenology of how he actually experienced his transition remains hard to establish. We propose that Swedenborg should not be scored at 2 on this item, for which he would have to be said clearly to have left the body and existed outside of it. He can, however, be said to have lost awareness of his body to some degree, and we hence allocate a score of 1 on this item.

The final four items on the NDE Scale address transcendental aspects of the experience. Items 13 and 14 address whether the individual felt they entered some other, unearthly realm, and whether they encountered there a mystical being or presence. This was certainly the case for Swedenborg, as his experiences typically involved entering a "spiritual world" (e.g., 1771/1883, n280) in which he encountered "things of another life" (1749-1756/1872, n1619) as well as mystical beings such as spirits, angels, and demons. Swedenborg's experiences hence score 2 for both these items, meeting Greyson's (1985) criteria of involving a "clearly mystical or unearthly realm" and a "definite being, or voice clearly of other-worldly origin." 
Item 15 involves the individual seeing deceased spirits or religious figures. Consistent with this phenomenon, Swedenborg claimed to have "conversed almost with all with whom I was acquainted during their life in the body" (1749-1756/1872, n1636) during his experiences. Furthermore, he also claimed to meet and speak with well-known figures including Aristotle, Descartes, and Leibniz (1771/1883, n696). Thus, we found Swedenborg's experiences meet the criteria for a score of 2 on this item.

Finally, item 16 involves assessing whether the individual came to a border or point of no return. Going through doors or across limits during NDEs is commonly interpreted as entering into heaven, and many individuals turn back at this point. For example, one individual reported hearing a voice during an NDE saying, "[G]o back. Your work on earth has not yet been completed" (Moody, 1975, p. 72). Swedenborg reported similar experiences, although they did not appear frequently in his reports. As noted above, he understood that after death individuals entered a spiritual realm that was a form of holding zone between heaven and hell. The transfer from this holding zone to Heaven and Hell occurred through "gates and doors" (1758/1931, n429). The gates and doors to hell appeared "dusky and as it were sooty caverns, tending obliquely downwards to the deep, where again there are several doors" (n429). However, these phenomena do not really constitute barriers that Swedenborg was forbidden to cross. It seems fairer to rate Swedenborg as scoring 1 on this item, as his experiences did involve a return to the body, as we described previously.

In conclusion, as Table 1 shows, a conservative approach to Swedenborg's typical day-to-day experiences can be seen to result in a score of 16 on the NDE Scale. This score is well above the cut-off point of 7 required for classification as an NDE (Greyson, 1985). In addition to the experiences identified on the NDE Scale, it is also worth considering whether Swedenborg did-or did not-experience any other common facets of NDEs.

\section{Other Aspects of NDEs}

One notable feature of the NDE Scale is that Greyson (1985) did not include in it a number of items Moody (1975) considered integral to NDEs, such as the experience of passing through a dark tunnel. Greyson (1985) noted that, in the case of the dark tunnel experience, 
he excluded the phenomenon because, in a preliminary version of the NDE Scale, this item failed to correlate with the other Scale items. This finding suggests that the dark tunnel experience may not be specific to the NDE experience and instead may be experienced in a wide variety of altered states of consciousness (Greyson, 1985). We note in passing that Swedenborg did not report any such dark tunnel experiences. However, it is likely to prove fruitful to compare Swedenborg's experiences with other aspects of NDEs that Moody and others identified.

Ineffability. Moody (1975) claimed that individuals who undergo NDEs "uniformly characterize their experiences as ineffable, that is, inexpressible" (p. 25). Such comments are typically of the form, "there are no words to express what I am trying to say" (p. 25). Some, though not all, of Swedenborg's experiences had this characteristic. As noted above, Swedenborg's theological topography consisted of a heaven, a hell, and an intermediate holding realm into which humans pass after death. Swedenborg found the speech of what he referred to as angelic spirits, whom he understood to reside in heaven, typically to be "incomprehensible" (1749-1756/1872, n1643). Furthermore, in a passage with similarities to Moody's own phrasing, Swedenborg reported that "the speech of the celestial angels ... is ... ineffable and inexpressible" (n1647). Rhodes (1996) also noted this element of ineffability in Swedenborg's experiences.

However, by no means does ineffability characterize all of Swedenborg's communications or descriptions of NDEs (Moody \& Perry, 1988). As noted above, Swedenborg occasionally reported that he had "been let into the state in which the angels are ... and then I understood all that was said" (1758/1931, n239). Furthermore, when communicating with non-angelic spirits who he claimed to inhabit the realm between heaven and hell, Swedenborg typically found such spirits' voices clearly understandable. For example, Swedenborg reported that he heard other spirits' voices "as sonorously as the speech of man" (1749-1756/1872, n4652). Indeed, the dominant form of Swedenborg's experiences appears to be comprehensible, didactic conversations (Benz, 2002).

The noise. Moody (1975) reported that NDErs describe having heard during their NDEs "various unusual auditory sensations" (p. 29) that may have taken the forms of "a loud click, a roaring, a banging, and ... a 'whistling sound like the wind"' (p. 29). In line with this description, 
some of Swedenborg's visions began with such auditory experiences (see Benz, 2002, p. 310). For example, before one vision, Swedenborg reported hearing "a noise like the roaring of the sea under my feet" $(1771 / 1883, \mathrm{n} 71)$, and on another occasion, a "gurgling sound, like that of bubbles" (n332) preceded a vision. A noise also occurred during what Toksvig (1948) argued to be the key transformational experience in Swedenborg's life, his 1744 vision of Jesus. During this experience, Swedenborg "heard a noise under my head ... [and] a thundering noise as if many winds beat together" (Dream Diary, n51-52). However, noises preceding Swedenborg's experiences were not typical of his experiences.

Telling others. Moody (1975) noted that individuals who had undergone an NDE typically had "no doubt whatsoever as to its reality," reporting that the experience was "nothing like a hallucination" or was "so real" (p. 80). Furthermore, such individuals realized that contemporary society would not be sympathetic to such experiences and would be likely to treat experiencers as mentally unstable. Reports such as "I don't like telling people about it. People just kind of look at you like you're crazy" (p. 81) were common. Moody further noted that such individuals were reticent to share their experiences, stating, "no one in my experience has built himself a portable lectern and gone out to preach about his experiences on a fulltime basis" (p. 84).

Swedenborg's attitude towards his experiences had much in common with these reported attitudes of NDErs. First, he was acutely aware that he might have been considered mad, writing of individuals who "persuaded others that I was insane" (1746-1765/1883, n2772). Similarly, he wrote that he was "well aware that many will say that no one can possibly speak with spirits and angels ... and many will say that it is all fancy, others that I relate such things in order to gain credence, and others will make other objections. But by all this I am not deterred, for I have seen, I have heard, I have felt" (1749-1756/ 1872 , n68). Swedenborg vigorously denied that his visions were hallucinations, or "phantasy" as he termed it (e.g., 1746-1747/1928, n7386).

Effects on lives. Moody (1975) noted that many individuals say their NDEs have caused their lives to be broadened or deepened and that they have become more concerned with ultimate philosophical issues. In the words of Melvin Morse and Perry's (1992) book title, people who 
have experienced NDEs are "transformed by the light." Swedenborg's experiences led to a radical reappraisal of his life and a shift away from scientific towards spiritual investigations. Moody also noted that a small number of individuals who have undergone NDEs claim to have developed psychic abilities as a consequence of the experiences. Swedenborg certainly claimed such abilities (Benz, 2002).

New views of death. Moody (1975) noted that nearly all individuals who experience NDEs report that they are subsequently no longer afraid of death. Swedenborg appears to have had a positive view of death, coming to view it as a "continuation of life" (1749-1756/1872, $\mathrm{n} 70$ ). When Swedenborg died at age 84, one of his contemporaries reported that "he was pleased, as if he was going to have a holiday, to go on some merry-making" (Toksvig, 1948, p. 361).

Associated anomalous experiences. In addition to the 15 features Moody (1975) highlighted, Swedenborg's reports show parallels with anomalous experiences NDErs reported having occurred before and/or after, but not during, their NDEs. One example is automatic writing. As noted above, Swedenborg produced much of The Word Explained, as well as his Spiritual Diary, through automatic writing. For example, he claimed that in the process of writing The Word Explained, he had "written entire pages, and the spirits did not dictate the words but absolutely guided my hand, so that it was they who were doing the writing" (1746-1747/1928, n1150). In the passages in which Swedenborg claims his hand was being guided, his handwriting differs from his normal hand, having an angular, slashing style (Toksvig, 1948). In this regard, his reports resemble the reports of two individuals Leister (1998) interviewed who also described experiences of automatic writing after their NDEs. One individual reported that at times she "finds herself writing notes to herself, although she has no conscious awareness of this process" (p. 242), and another claimed that "words will flow through me onto paper" (p. 239).

Another research finding is that both before and after their NDEs, experiencrs commonly report having hallucinatory experiences during clear consciousness (Leister, 1998). For example, in a sample of individuals who had experienced an NDE 10 or more years ago, Morse and Perry (1992) found that $12 \%$ continued to have regular contact with the same angels they saw during their NDEs, and more than $10 \%$ reported seeing "ghosts or other apparitions" (p. 164) following their 
NDEs. Consistent with such findings, Swedenborg experienced a whole range of anomalous hallucination experiences (Jones \& Fernyhough, 2008).

\section{Conclusions}

What can be concluded from the above review? Using Greyson's (1985) NDE Scale, Swedenborg's experiences may be identified as meeting the criteria for an NDE. The affective and transcendental components of the NDE Scale show strong parallels with Swedenborg's experiences. Swedenborg's experiences can also be seen to have much in common with other facets of NDEs that Moody (1975) identified. Furthermore, Swedenborg described other anomalous experiences that NDErs also have described. However the cognitive and paranormal components of the NDE Scale are less applicable to his experiences. Swedenborg's cognitive faculties while in the 'spiritual world' appear to have remained broadly consistent with his normal functioning, save for the perceived ability to communicate via thought transfer rather than speech. Similarly, a number of Moody's (1975) facets of NDEs, such as the dark tunnel, do not appear in Swedenborg's descriptions of his experiences. Likewise, the physical transition between the material world and the 'spiritual realm', which NDErs have commonly reported (e.g., Greyson \& Stevenson, 1980), does not figure strongly in Swedenborg's reports.

However, overall, the extensive parallels between Swedenborg's experiences and NDEs arguably suggest a potential common causal factor behind both. This speculation brings us to our second main question, which concerns common mechanisms that may underlie Swedenborg's experiences and NDEs.

\section{Mechanisms Underlying Swedenborg's Experiences and NDEs}

\section{Cerebral Hypoxia}

One factor that has been argued to play a causal role in NDEs, as well as being prominent in Swedenborg's life, is cerebral hypoxia. We first discuss what cerebral hypoxia is, and then examine its potential to have a causative role in NDEs, before turning to an examination of its occurrence in Swedenborg. 
Hypoxia and NDEs. Cerebral hypoxia, a decreased oxygen supply to the brain, may occur for a variety of reasons. First, reduced atmospheric oxygen or obstruction of the airways can result in an insufficient concentration of oxygen in the blood. Second, in conditions such as anemia and carbon monoxide poisoning, although ample oxygen is available, the blood is unable to transport it efficiently. Finally, in conditions such as strokes, cardiac arrest, or extreme g-forces, despite ample oxygen in the blood, its supply to the brain may be interrupted.

Many researchers have found that hypoxia can cause hallucinatory experiences with some phenomenological parallels to NDEs. First, a reduction in respiration rate can induce altered states of consciousness, including hallucinatory experiences (Vaitl et al., 2005). In such experiences, slow breathing - hypoventilation - can cause increases in carbon dioxide $\left(\mathrm{CO}_{2}\right)$ concentrations in the blood, termed hypercapnia (Vaitl et al.). A simple method of inducing hypercapnia experimentally is through inhaling $\mathrm{CO}_{2}$-enriched air. Using this technique, Laszlo von Meduna (1950) found that hypercapnia can result in experiences with some parallels to NDEs, such as bodily detachment and the perception of being drawn toward a bright light. Although Pavel Terekhin (1996) failed to replicate this finding, Dieter Vaitl et al. (2005) argued that the failure was due to methodological differences in the amount and duration of $\mathrm{CO}_{2}$ used to induce hypercapnia. Based on work with pilots who have experienced ischemic hypoxia due to the presence of extreme g-forces, James Whinnery (1997) has also proposed that hypoxia may cause hallucinatory experiences with parallels to NDEs. Pilots reported a range of experiences including seeing bright lights and experiencing vivid semi-conscious "dreamlets" (p. 244) involving encounters with family and close friends. However, it has been argued that the experiences research participants described in both Whinnery's (1997) and Meduna's (1950) studies do not parallel NDEs very closely. For example, Edward Kelly, Emily Kelly, Adam Crabtree, Alan Gauld, Michael Grosso, and Greyson (2006) argued that in Whinnery's (1997) study, the parallels to NDEs were limited, including as they did convulsions and seeing living-as opposed to deceased-individuals.

More convincing evidence for the potential of hypoxia to result in NDEs comes from a number of experimental studies in which researchers empirically investigated the effects of cerebral hypoxia on cognition. For example, Thomas Lempert, Martin Bauer, and 
Dieter Schmidt (1994) caused 42 healthy young adults to reach the stage of fainting (syncope) by having them hyperventilate and perform the Valsalva maneuver. This maneuver involves forcibly exhaling while the mouth is closed and nose is pinched to prevent air from escaping from these orifices. During syncope, participants reported visual hallucinations, such as seeing colours and lights that sometimes intensified to a glaring brightness. They also reported more complex visual hallucinations, including those of landscapes and familiar people; auditory hallucinations ranging from roaring noises to screaming or unintelligible human voices; and out-of-body experiences. They described the emotional valence of the experience as pleasant, detached, and peaceful, making participants unwilling to return.

Lempert et al. (1994) noted that not only did their procedure evoke hallucinatory experiences but that these experiences took the form of NDEs. Specifically, the researchers stated that "our experiment confirms the potency of cerebral hypoxia to induce near-death experiences" (p. 830). Indeed, two participants reported parallels with NDEs they had earlier experienced as a result of traumatic events. However, a number of differences between such experiences and NDEs still remain. First, the short duration of such events meant that the visions research participants experienced were only fragmentary and were not of the coherent narrative form typically found in NDEs. Second, the visions were not interactive: Participants did not report interacting with the figures in their visions to any significant degree, which is a notable feature of NDEs.

Even if cerebral hypoxia were able to cause NDEs, it may not be a necessary cause of them (Blackmore, 1998). For example, Pim van Lommel, Ruud van Wees, Vincent Meyers, and Ingrid Elfferich (2001) found that only $18 \%$ of cardiac arrest survivors-who had been clinically dead-reported NDEs. Furthermore, in a study of blood gases in a patient during an NDE, results showed normal levels (Sabom, 1982). In a later study Sam Parnia, Derek Waller, Rebecca Yeates, and Peter Fenwick (2001) also examined blood oxygen and carbon dioxide levels during cardiac arrest and compared levels in those who had NDEs $(N=4)$ and those who had not. They found blood oxygen levels to be higher-not lower-in the NDE group. In addition to the small sample sizes, one weakness of such studies is the researchers' inability to match the time of taking blood with the exact time at which the NDE occurred. Furthermore, as cardiac arrest involves the cessation of blood being pumped to the brain, as well as 
the rest of the body, actual oxygen levels in the blood should be of only minimal relevance. Once equilibration has taken place between the oxygen levels in the cerebral blood and those in cerebral tissue, no more will be delivered until blood flow resumes.

A further criticism of the proposed causal role for hypoxia in the generation of NDEs comes from Greyson (2006). He claimed that hypoxia generally produces "idiosyncratic, frightening hallucinations and leads to agitation and belligerence, quite unlike the peaceful NDE with consistent, universal features" (p. 397). However, Lempert et al.'s (1994) study demonstrated that hypoxia-induced hallucinations are not necessarily associated with negatively valenced experiences. Likewise, NDE hallucinations associated with non-life-threatening reflex anoxia seizures in children are also of various valences (Blackmore, 1998). It thus may be only when an uncontrollable traumatic event causes hypoxia that ensuing hallucinations are negative. We speculate that when the hypoxia is a controlled event, the lack of state anxiety associated with the event may have a corresponding influence on the emotional valence of the experience.

In conclusion, it appears that hypoxia may be able to create experiences with some parallels to NDEs. However, researchers have investigated only brief, single hypoxic episodes. In such studies, hypoxia typically results in only superficial resemblances to NDEs, with visions not being interactive, being of living (as well as dead) people, and being more fragmentary than the coherent narrative type experiences of NDEs. It remains for future research to determine why some hypoxic states may have similarities with NDEs and not others, and to examine how more frequent hypoxic events may alter the phenomenology of the hypoxic episodes, or the probability of NDEs occurring. One way to investigate this question could be to examine the prevalence of NDEs and NDE-like experiences in high-altitude mountaineers in whom researchers have found hypoxic states cause numerous permanent neural changes (e.g., Garrido, Castello, Ventura, Capdevila, \& Rodriguez, 1993). Indeed, Shahar Arzy, Moshe Idel, Theodor Landis, and Olaf Blanke (2005) have speculated that Biblical and other mystical experiences (although not specifically NDEs) that people experienced on mountains may have resulted from hypoxia preferentially affecting areas of the cerebral cortex that researchers have linked to disturbed own-body perceptions and mystical experiences. Factors such as the context of the hypoxic state and the personality of the sufferer, in conjunction with their life history and 
temporal lobe reactivity (discussed further below), may need to be considered. In summary, although other factors are likely to be involved in many cases of NDEs, there is evidence that hypoxia may play a contributory role in some such cases. We now turn to address how and why Swedenborg came to be exposed to hypoxic states.

Hypoxia as a proximal cause of Swedenborg's experiences. The cause of Swedenborg's experiences may lie in a phenomenon that Swedenborg himself reported: his ability to slow his rate of respiration. Swedenborg noted that ever since his childhood he had been able to breathe in a "scarcely perceptible" way (Benz, 2002, p. 158). This breathing technique appears to have consisted of suppression of his breathing in order to focus thought (p. 158). Such a technique has parallels in contemporary Zen and Yoga practices in which focused attention on breathing allows slow and shallow respiration as part of the meditative process (Vaitl et al., 2005). For example, members of the Japanese Zen sect of Rinzai give special emphasis to the skill of breath control, and their training in very slow and quiet breathing can result in respiration rates less than $1 \mathrm{breath} / \mathrm{min}$ (Lehrer, Sasaki, \& Saito, 1999).

It is unclear whether Swedenborg's reduction of his respiration rate was wholly, partly, or not at all under his conscious control. Partial control appears the most probable option. Evidence that he suffered from a form of sleep apnea, where breathing intermittently stops during sleep (Banno \& Kryger, 2007), suggests that it was not entirely under his conscious control. For example, Swedenborg reported that he "repeatedly noticed that I stopped breathing after I had fallen asleep, and gasped for air when I awoke" (Swedenborg cited in Benz, 2002 , p. 158). He also spoke of awaking one night and believing that spirits that "conspired against me with the purpose of suffocating me" (1746-1765/1883, n458). Swedenborg reported such reduced respiration rates also during the day. He noted that when such incidents occurred, his heart rate and breathing sometimes coincided. For example, he stated that "the terminations of the heart's time closed in the pulmonic beats, and were related to each other" (ibid, n1615).

After Swedenborg had been having anomalous experiences for some years, he made the direct link between his controlled breathing and his spiritual experiences, claiming that "my respiration was so formed by the Lord that I could respire inwardly for a considerable time, without the aid of external air... in order that I may be with spirits and speak with them" (1746-1765/1883, n3317). He stated that "when 
heaven was opened to me, and I was enabled to converse with spirits, I sometimes scarcely breathed" (n3464). It hence appears likely that Swedenborg's hypoventilation is a likely candidate for a proximal cause of his experiences. Indeed, Benz (2002) has already noted that "one cannot dismiss the possibility that Swedenborg's varied visionary experiences... are related to this phenomenon" (p. 159). However, Benz has not considered in any detail the contemporary scientific evidence that might support or refute the involvement of such a mechanism, and how it may have acted as both a proximal and distal cause.

\section{Distal Causes of Swedenborg's Experiences}

Although it seems plausible that hypoxia may have been a proximal cause of Swedenborg's experiences, the question of distal causation, or etiology, remains. In this section, we consider two possible distal causes. The first is that a single traumatic event led to Swedenborg undergoing ongoing anomalous experiences. The second is that hypoxia over a long period of time, existing in Swedenborg's case since childhood, led to a developmental trajectory in which individual hypoxic events came to be more likely to result in unusual experiences than they would in the general population. We deal with these possibilities in turn.

A one-time traumatic event. Several researchers have found that traumatic experiences, such as war (Butler, Mueser, Sprock, \& Braff, 1996) and childhood abuse (e.g., Read \& Argyle, 1999), as well as NDEs (Greyson \& Leister, 2004; Leister, 1998), appear to serve as kindling events whereby, in their aftermath, people have continuing anomalous experiences such as hallucinations. With regard to Swedenborg, the major problem with this 'kindling event' dynamic is that it is hard to pinpoint such an event in Swedenborg's life. The most likely event would be the April 1744 nighttime experience of seeing Jesus. However, as noted above, the form and content of Swedenborg's experiences evolved over his lifetime, from early vivid dreams and hypnagogia pre-1744, to his later visions. It hence appears more probable that some more incremental process contributed to Swedenborg's experiences.

A gradualistic account of Swedenborg's experiences. As noted earlier, since childhood, Swedenborg had been able to control his 
breathing. It is thus possible that Swedenborg's developmental trajectory could have been affected by his early and continued hypoventilation. It is already known that both schizophrenia (e.g., Zornberg, Buka, \& Tsuang, 2000) and epilepsy (Bergamasco, Benna, Ferrero, \& Gavinelli, 1984) are associated with fetal hypoxia and hypoxia due to obstetric complications. It would, therefore, appear plausible that proneness to NDEs may also be increased by early hypoxia. Animal studies have shown that early hypoxia can lower future seizure thresholds (Koh, Tibayan, Simpson, \& Jensen, 2004; Owens, Robbins, Wenzel, \& Schwartzkroin, 1997) as well as lead to greater neural excitability (Jensen \& Baram, 2000). It is also known that intermittent hypoxia selectively activates certain genes, downregulating some while upregulating others (Prabhakar, 2001). In particular, hypoxia appears to regulate a number of genes associated with schizophrenia (Schmidt-Kastner, van Os, Steinbusch, \& Schmitz, 2006). Although this process is still not understood in detail, it appears plausible that Swedenborg's neural activity may have been influenced by such genetic activity. Similarly, researchers have found that the hypoxia, hypercapnia, and brief blood pressure elevations resulting from sleep apnea cause changes in the temporal lobe (Macey et al., 2002). This finding supports proposals that hypoxia can hypersensitize neurons and lower seizure thresholds, particularly in the temporal lobe (e.g., Benveniste, Brejer, Achouseboe, \& Diemer, 1984) where a high prevalence of interictal temporal lobe epileptiform EEG activity is found in people who have had NDEs (Britton \& Bootzin, 2004).

We hence propose that Swedenborg's experiences resulted from an atypical developmental trajectory shaped by hypoxia resulting from hypoventilation. This developmental trajectory led to the evolution of Swedenborg's experiences over a period of decades, from unusual dreams and brief experiences in the hypnagogic state, to much more substantial experiences in the hypnagogic state and hallucinations in clear consciousness with form and content paralleling NDEs. We propose that the development of these experiences could have been caused by the continuing hypersensitizing of neurons and lowering of seizure thresholds, especially in the temporal lobe. This development would account not only for the NDE-like experiences that Swedenborg came to have but also other of his experiences that do show parallels to epileptic seizures (Jones \& Fernyhough, 2008); for example, unusual olfactory and tactile experiences. 
Some critics might object that if this hypoxic process were the case, then Swedenborg should have manifested other significant, long-term neurocognitive effects, such as memory impairment (Yonelinas et al., 2002). However, as Fenella Kirkham and Avijit Datta (2006) noted, an individual's reaction to hypoxia depends on "genetic factors and on the timing, degree and duration of exposure" (p. 414), and some evidence indicates that hypoxia and hypercapnia do not necessarily lead to pervasive developmental changes (McCray, Crockett, Wagener, \& Thies, 1988). Similarly, even if Swedenborg's hypoventilation did lead to an alternative developmental trajectory, this process would presumably still have resulted in the development of unimpaired cognitive abilities, albeit potentially through atypical developmental pathways (Karmiloff-Smith, 1998).

The observation that many contemporary Zen practitioners do not report parallels to Swedenborg's experiences, even though they have undergone extensive breath-control training, suggests that such continued hypoxia may not be a sufficient cause of Swedenborg's experiences. Therefore, he likely had some predisposition to such experiences. One possibility is that he inherited a tendency to lower seizure thresholds in the temporal lobe. Although little evidence exists for this hypothesis, some signs of hypergraphia and an intense religiosity in his father, which have been associated with epilepsy, could be considered supportive of it. To be clear, we are not claiming that Swedenborg suffered from epilepsy, as Swedenborg's experiences are not consistent with the hallucinatory experiences sometimes associated with epilepsy (Jones \& Fernyhough, 2008). Rather, our proposal is that a predisposition to temporal lobe seizures, in conjunction with neural changes due to long-term hypoventilation since childhood, led to his experiences.

Such an account offers a developmental explanation for the dilemma of how Swedenborg was able to have NDE-like experiences in clear consciousness. Repeated experiences of hypoxia throughout his childhood may have sensitized his temporal lobe neurons such that hypoxia that would facilitate an NDE in most adults only as they lost consciousness facilitated NDE-like experiences in Swedenborg during conscious states as well.

\section{Hypnagogia}

As part of the above model, we have proposed that Swedenborg's hypnagogic experiences were a step in the developmental progression 
to a qualitatively different type of hallucinatory experience that had parallels to NDEs. Critics might object that all Swedenborg's experiences, and potentially many aspects of NDEs (e.g., Nelson, Mattingly, Lee, \& Schmitt, 2006), were simply a form of hypnagogic hallucinations, in that they were intrusions from REM sleep into waking consciousness. In a related proposal, J. Allan Hobson (1999, 2002) has suggested that Swedenborg's experiences resulted from "keeping himself awake all night then letting himself sleep fitfully by day" (p. 131) and undertaking "intentional sleep deprivation" (2002, p. 95). This, Hobson claimed, caused an imbalance in Swedenborg's aminergic-cholinergic system that, in turn, facilitated the impulsive firing of vision neurons, resulting in his hallucinations. In order to examine this proposition, we will examine briefly the parallels between Swedenborg's experiences and hypnagogic phenomena as well as his sleeping patterns.

Hobson $(1999,2002)$ did not provide details about the source of his claims that Swedenborg kept himself awake all night and slept fitfully during the day and that he undertook intentional sleep deprivation. One possible source for this claim is a text that William White (1867) wrote almost 100 years after Swedenborg's death in which he noted that Swedenborg paid little regard to night and day "sometimes sleeping through the one and working through the other" (p. 341, italics added). However, the basis for White's claim is the report of Swedenborg's friend and contemporary, Carl Robsahm, the treasurer of a Stockholm bank. Robsahm's (1782, as cited in Tafel, 1875a) account indeed related that Swedenborg "never had any definite time for sleeping" (p. 33), but he also noted that Swedenborg told him, "When I am sleepy, I go to bed" (p. 32). This practice is very different from the practice of intentional sleep deprivation. At other points in his life, Swedenborg seems to have practiced more fixed sleeping patterns. For example, Swedenborg noted in his Dream Diary that around the time of his first significant visions in 1744-1745, he usually went to bed around 9:00 p.m. and slept for 10-12 hours. Consistent with this report, one of his friends observed that Swedenborg slept "pretty long, and thirteen hours are not too much" (Tafel, 1875b, p. 482). In his later years, Swedenborg's housekeeper noted that "every evening he goes to bed at [7:00], and gets up in the morning at [8:00]" (Tafel, 1875b, p. 446). The available evidence hence does not appear to support Hobson's claims of a nocturnal lifestyle, fitful sleep, and intentional sleep deprivation. 
The second question is whether Swedenborg's experiences showed phenomenological parallels to hypnagogic phenomena. One property of such experiences, such as faces seen during this state, is that they are often more vivid than a normal face seen in the waking state (Leaning, 1925; Schacter, 1976). For example, Mavromatis (1988) noted that "[hypnagogic images] are so sharp and detailed, as one subject put it in respect to faces, 'I could see the grain of the skin"' (p. 29). Similarly, hypnagogic scenes of landscapes and buildings very often possess qualities of unusual color, grandeur, and beauty (Leaning, 1925; Mavromatis, 1988). All these facets show parallels with Swedenborg's experiences and would lead to the endorsement of item 9 on Greyson's (1985) NDE Scale (see Table 1). Similarly, hypnagogic images can be associated with the presence of intense light that experiencers describe as mystical, having "a strange luminosity" or being like "liquid fire" (Leaning, 1925, p. 339). Such experiences would lead to endorsement of item 8 on the NDE Scale. Furthermore, the finding that meditative breathing practices may induce hypnagogic imagery (Mavromatis, 1988) again suggests that Swedenborg's experiences may have been a form of hypnagogic phenomenon.

As some of Swedenborg's experiences occurred in the hypnagogic state, such parallels should not be surprising. However, Swedenborg's visions often exhibited a number of features very unusual for hypnagogic phenomena but common in NDEs. Indeed, Swedenborg's experiences represent more differences than commonalities with hypnagogic phenomena. First, Andreas Mavromatis (1988) noted that "not only are strong emotions rare in [the hypnagogic] state but also that their occurrence is not conductive to ... hypnagogia," and that "most subjects report that they experience 'relaxed numbness" or are merely "disinterested" (p. 62). This emotional quality is in stark contrast to the strong affective states that Swedenborg often reported in association with his experiences. Second, hypnagogic scenes containing people typically have no beginning or end (Mavromatis). As noted above, Swedenborg's typical visions often involved him being invited somewhere and then returning 'home.' Third, speech in the hypnagogic state consists of "on the whole ... apparently nonsensical or irrelevant statements" (Mavromatis, p. 42). This description does not fit with Swedenborg's experiences. On a related point, like Wilson Van Dusen (1972), Daniel Schacter (1975) noted that "as one moves deeper into the hypnagogic state, thought and ideation become 
increasingly bizarre [and] less amenable to conscious control" (p. 466). In contrast, Swedenborg portrayed his experiences as rational and clear. Fourth, hypnagogic hallucinations may involve encounters, through various modalities, with both the living and dead (Mavromatis, 1988); however, like the vast majority of NDErs, Swedenborg reported encountering only individuals whom he knew to be dead. Furthermore, most hypnagogic imagery is later understood to be illusory and not reality-based, which contrasts with the conviction of reality Swedenborg had of his experiences-and most NDErs have of theirs. Although, as noted earlier, Swedenborg claimed he could have understood his pre-1744 experiences as "phantasy," this was not the case with his post-1744 experiences.

It therefore appears that even if some of Swedenborg's experiences were a form of hypnagogia, his experiences evolved into something very unlike typical hypnagogic hallucinations, instead having marked parallels with NDEs. This perspective is consistent with the wider argument that hypnagogic hallucinations are "qualitatively different" from NDEs (Long \& Holden, 2007, p. 164).

Having established that the phenomenology of Swedenborg's experiences was actually rather different from hypnagogic experiences, it is worth examining a testable implication of our model: that although NDEs are a separate class of phenomenon to hypnagogic experiences, hypnagogia may precede or act as a vulnerability marker for NDEs. Swedenborg's case seems to support the hypothesis that people who report having had an NDE during a close brush with death will report higher rates of hypnagogia in the years preceding the NDE than those who do not report an NDE during a close brush with death. As Jeffrey Long and Janice Holden (2007) noted, the claim that hypnagogic phenomena may act as a vulnerability marker within a diathesis-stress model of NDEs is already to be found in the work of Kevin Nelson et al. (2006). Nelson et al. found hypnagogic phenomena to be more common in people who had experienced NDEs than in control participants, and they went on to propose that people who experience NDEs have arousal systems that predispose them to hypnagogic hallucinations (REM intrusions). However, Nelson et al. did not establish whether the hypnagogic hallucinations preceded or post-dated the occurrence of the NDEs. Long and Holden (2007) noted a number of other limitations of Nelson et al.'s research, and further empirical and theoretical research remains to be performed into the relationship between these two sets of phenomena. 


\section{Conclusions}

In this article we examined the commonalities, as well as the differences, between Swedenborg's experiences and NDEs. By employing Greyson's (1985) Near-Death Experience Scale, we concluded that Swedenborg's experiences could be identified as NDEs. In particular, the affective and transcendental components of this scale clearly resonate with the phenomenology of Swedenborg's experiences. We also found in Swedenborg's visions other facets of NDEs that Moody (1975) had identified, such as the sometimes ineffable nature of his experiences and the effect of them on his life. Furthermore, Swedenborg experienced a range of other anomalous experiences similar to those that individuals who have undergone NDEs have reported. Contrastingly, we found that the cognitive and paranormal components of the NDE Scale were less applicable to Swedenborg's experiences, as his cognitive faculties remained broadly consistent with his normal functioning. A number of Moody's (1975) facets of NDEs, such as the dark tunnel, also do not appear in Swedenborg's writings. A lack of emphasis on the physical transition between the material world and the spiritual realm also differentiates Swedenborg's reports from some contemporary NDEs. That said, Swedenborg's experiences can broadly be seen as NDE-like experiences. We have proposed that the parallels between Swedenborg's experiences and NDEs suggest potential common contributory pathways behind both.

After reviewing evidence suggesting that hypoxia may contribute to some, but by no means all, NDEs, we have argued that a proximal cause of Swedenborg's experiences was cerebral hypoxia. In terms of distal causation of Swedenborg's experiences, we have argued that the existence of his altered patterns of respiration since childhood, possibly in conjunction with a predisposition to temporal lobe seizures, contributed to a proneness to such experiences.

However, we want to emphasize that we do not mean to claim that an account of Swedenborg's experiences at the physiological level is a sufficient or complete explanation of them. Attention must be paid to the context of his experiences, occurring as they did in a profound spiritual crisis. This crisis involved the clash of his orthodox Lutheran background with his scientific self, and a painful inability to believe without reasoning (Toksvig, 1948). Seen in this context, Swedenborg's experiences are consistent with what John Watkins (2008) has termed 
hallucinations stemming from a psychospiritual crisis and can be seen as an idiosyncratic attempt to solve the questions arising from his crisis. However, Silvano Arieti (1979) has noted that an individual undergoing hallucinatory experiences would "probably not attempt to solve his problems in this abnormal way if he were not inclined to do so by a biological predisposition, or an unusual conglomeration of psychological factors, or a mixture of psychological and physical factors" (p. 46). In line with this reasoning, we would argue that Swedenborg's experiences are best understood as being an idiosyncratic response to an intense psychospiritual crisis that took the form it did due to his prior hypoxic developmental experiences in conjunction with a predisposition to temporal lobe seizures.

Critics might observe that some of the arguments we advanced in this article are, due to the historical nature of the subject, necessarily speculative. That said, we have also pointed to a number of directions for future empirical work. First, it would be interesting to examine whether there is a greater prevalence of NDEs in those who have had a lifetime of exposure to hypoxic states, such as those involved in meditative breathing practices or high altitude mountaineering. Second, are early hypoxic experiences (such as fetal hypoxia) and events associated with these experiences (e.g., birth complications) associated with the tendency to experience NDEs? Similarly, what developmental factors associated with the sensitization of the temporal lobe correlate with prevalence of NDEs? Such a developmental approach to NDEs may prove fruitful in furthering an understanding of their causes.

Finally, some readers may wonder what our account of the development of Swedenborg's experiences might reveal about their theological or spiritual dimensions. If the occurrence of such experiences is seen as resulting from internally generated neural events, this dynamic would appear to argue against theological interpretations of such experiences as being influxes from an external, supernatural entity with an objective ontological status. However, others (e.g., Fenwick, 2004; van Lommel, 2004) have argued that the dependency of psychological processes on brain function is an unproved assumption; people holding this perspective would consider the neural argument incomplete. We would argue that the potential role for biological processes in Swedenborg's experiences in no way detracts from the novelty, insight, alivenness, and moral revelations that may characterize such experiences. Perhaps Swedenborg's 
ultimate legacy may not be what he tells us about a Divine Being but his illustration of the richness of what may lie within us all.

\section{References}

Arieti, S. (1979). Understanding and helping the schizophrenic: A guide for family and friends. New York: Basic Books.

Arzy, S., Idel, M., Landis, T., \& Blanke, O. (2005). Why revelations have occurred on mountains? Linking mystical experiences and cognitive neuroscience. Medical Hypotheses, 65, 841-845.

Athappilly, G. K., Greyson, B., \& Stevenson, I. (2006). Do prevailing societal models influence reports of near-death experiences? A comparison of accounts reported before and after 1975. Journal of Nervous and Mental Disease, 194, 218-222.

Banno, K., \& Kryger, M. H. (2007). Sleep apnea: Clinical investigations in humans. Sleep Medicine, 8, 400-426.

Benveniste, H., Brejer, J., Achouseboe, A., \& Diemer, H. (1984). Elevation of the extracellular concentrations of glutamate and aspartate in rat hippocampus during cerebral ischemia monitored by microdialysis. Journal of Neurochemistry, 43, $1369-1374$.

Benz, E. (2002). Emanuel Swedenborg: Visionary savant in the Age of Reason (N. Goodrick-Clarke, Trans.). West Chester, PA: Swedenborg Foundation.

Bergamasco, B., Benna, P., Ferrero, P., \& Gavinelli, R. (1984). Neonatal hypoxia and epileptic risk: A clinical prospective study. Epilepsia, 25, 131-136.

Blackmore, S. (1998). Experiences of anoxia: Do reflex anoxic seizures resemble NDEs? Journal of Near-Death Studies, 17, 111-120.

Bradford, D. T. (1999). Neuropsychology of Swedenborg's visions. Perceptual and Motor Skills, 88, 377-383.

Britton, W. B., \& Bootzin, R. R. (2004). Near-death experiences and the temporal lobe. Psychological Science, 15, 254-58.

Butler, R. W., Mueser, K. T., Sprock, J., \& Braff, D. L. (1996). Positive symptoms of psychosis in posttraumatic stress disorder. Biological Psychiatry, 39, 839-844.

De Boismont, A. B. (1860). On hallucinations. (R. T. Hulme, Trans.). Columbus, $\mathrm{OH}$ : Joseph H. Riley.

Fenwick, P. (2004). Science and spirituality: A challenge for the 21st century. Journal of Near-Death Studies, 23, 131-157.

Foote-Smith, E., \& Smith, T. J. (1996). Emanuel Swedenborg. Epilepsia, 37, 211-218.

Garrido, E., Castello, A., Ventura, J. L., Capdevila, A., \& Rodriguez, F. A. (1993). Cortical atrophy and other brain magnetic resonance imaging (MRI) changes after extremely high-altitude climbs without oxygen. International Journal of Sports Medicine, 14, 232-234.

Greyson, B. (1985). The Near-Death Experience Scale. Journal of Nervous and Mental Disease, 171, 369-375.

Greyson, B. (2000). Dissociation in people who have near-death experiences: Out of their bodies or out of their minds? Lancet, 355, 460-463.

Greyson, B. (2003). Incidence and correlates of near-death experiences in a cardiac care unit. General Hospital Psychiatry, 25, 269-276.

Greyson, B. (2006). Near-death experiences and spirituality. Zygon, 41, 393-414.

Greyson, B., \& Leister, M. B. (2004). Auditory hallucinations following near-death experiences. Journal of Humanistic Psychology, 44, 320-336.

Greyson, B., \& Stevenson, I. (1980). The phenomenology of near-death experiences. American Journal of Psychiatry, 137, 1193-1196. 
Hobson, J. A. (1999). Dreaming as delirium. Cambridge, MA: Massachusetts Institute of Technology Press.

Hobson, J. A. (2002). The dream drugstore: Chemically altered states of consciousness. Cambridge, MA: Massachusetts Institute of Technology Press.

Jackson, N. E., \& Coltheart, M. (2001). Routes to reading success and failure: Toward an integrated cognitive psychology of atypical reading. Hove, UK: Lawrence Erlbaum Associates.

James, W. (1960). The varieties of religious experience. London: Collins. (Original work published 1902)

Jaspers, K. (1962). General psychopathology. Manchester, UK: Manchester University Press. (Original work published 1923)

Jensen, F. E., \& Baram, T. Z. (2000). Developmental seizures induced by common earlylife insults: Short- and long-term effects on seizure susceptibility. Mental Retardation and Developmental Disabilities Research Reviews, 6, 253-257.

Johns, L. C., \& van Os, J. (2001). The continuity of psychotic experiences in the general populations. Clinical Psychology Review, 21, 1125-1141.

Jones, S. R., \& Fernyhough, C. (2008). Talking back to the spirits: The voices and visions of Emanuel Swedenborg. History of the Human Sciences, 21, 1-31.

Karmiloff-Smith, A. (1998). Development itself is the key to understanding developmental disorders. Trends in Cognitive Sciences, 2, 389-398.

Kelly, E. F., Kelly, E. W., Crabtree, A., Gauld, A., Grosso, M., \& Greyson, B. (2006). Irreducible mind: Toward a psychology for the 21st century. Lanham, MD: Rowman \& Littlefield.

Kirkham, F. J., \& Datta, A. K. (2006). Hypoxic adaptation during development: Relation to pattern of neurological presentation and cognitive disability. Developmental Science, 9, 411-427.

Koh, S., Tibayan, F. D., Simpson, J. N., \& Jensen, F. E. (2004). NBQX or topiramate treatment after perinatal hypoxia-induced seizures prevents later increases in seizure-induced neuronal injury. Epilepsia, 45, 569-575.

Leaning, F. E. (1925). An introductory study of hypnagogic phenomena. Proceedings of the Society for Psychical Research, 35, 289-403.

Lehrer, P., Sasaki, Y., \& Saito, Y. (1999). Zazen and cardiac variability. Psychosomatic Medicine, 61, 812-821.

Leister, M. B. (1998). Inner communications following the near-death experience. Journal of Near-Death Studies, 16, 233-248.

Lempert, T., Bauer, M., \& Schmidt, D. (1994). Syncope: A videometric analysis of 56 episodes of transient cerebral hypoxia. Annals of Neurology, 36, 233-237.

Long, J., \& Holden, J. M. (2007). Does the arousal system contribute to near-death and out-of-body experiences? A summary and response. Journal of Near-Death Studies, 25, 135-169.

Macey, P. M., Henderson, L. A., Macey, K. E., Alger, J. R., Frysinger, R. C., \& Woo, M. A., et al. (2002). Brain morphology associated with obstructive sleep apnea. American Journal of Respiratory and Critical Care Medicine, 166, 1382-1387.

McCray, P. B., Crockett, D. M., Wagener, J. S., \& Thies, D. J. (1988). Hypoxia and hypercapnia in infants with mild largygomalacia. American Journal of Diseases of Children, 142, 896-899.

Maudsley, H. (1869). Emanuel Swedenborg. Journal of Mental Science, 15, 417-436.

Mavromatis, A. (1988). Hypnagogia. London: Routledge.

Meduna, L. J. (1950). The effect of carbon dioxide upon the functions of the brain. In L. J. Meduna (Ed.), Carbon dioxide therapy (pp. 23-40). Springfield, IL: Charles C. Thomas.

Moody, R. A. (1975). Life after life. Covington, GA: Mockingbird.

Moody, R. A., \& Perry, P. (1988). The light beyond. New York: Bantam. 
Morse, M., \& Perry, P. (1992). Transformed by the light: The powerful effect of neardeath experiences on people's lives. New York: Villard Books.

Nelson, K. R., Mattingly, M., Lee, S. A., \& Schmitt, F. A. (2006). Does the arousal system contribute to near death experience? Neurology, 66, 1003-1009.

Owens, J., Robbins, C. A., Wenzel, H. J., \& Schwartzkroin, P. A. (1997). Acute and chronic effects of hypoxia on the developing hippocampus. Annals of Neurology, 41, 187-199.

Parnia, S., Waller, D. G., Yeates, R., \& Fenwick, P. (2001). A qualitative and quantitative study of the incidence, features and aetiology of near death experiences in cardiac arrest survivors. Resuscitation, 48, 149-156.

Parnia, S., \& Fenwick, P. (2002). Near death experiences in cardiac arrest: Visions of a dying brain or visions of a new science of consciousness. Resuscitation, 52, 5-11.

Posey, T. B., \& Losch, M. E. (1983). Auditory hallucinations of hearing voices in $\mathbf{3 7 5}$ normal subjects. Imagination, Cognition, and Personality, 3, 99-113.

Prabhakar, N. R. (2001). Physiological and genomic consequences of intermittent hypoxia. Journal of Applied Physiology, 90, 1986-1994.

Read, J., \& Argyle, N. (1999). Hallucinations, delusions, and thought disorder among adult psychiatric inpatients patients with a history of childhood abuse. Psychiatric Services, 50, 1467-1472.

Rhodes, L. (1996). Tunnel to eternity. West Chester, PA: Chrysalis.

Rhodes, L. S. (1982). The NDE enlarged by Swedenborg's vision. Anabiosis, 2, 15-35.

Sabom, M. B. (1982). Recollections of death. London: Corgi.

Schacter, D. L. (1976). The hypnagogic state: A critical review of the literature. Psychological Bulletin, 83, 452-481.

Schmidt-Kastner, R., van Os, J., Steinbusch, W. M., \& Schmitz, C. (2006). Gene regulation by hypoxia and the neurodevelopmental origin of schizophrenia. Schizophrenia Research, 84, 253-271.

Swedenborg, E. (1872). Arcana coelestia (J. Clowes, Trans.). London: The Swedenborg Society. (Original work published 1749-1756)

Swedenborg, E. (1883). The spiritual diary of Emanuel Swedenborg (G. Bush \& J. H. Smithson, Trans.). London: James Speirs. (Original work published 1746-1765)

Swedenborg, E. (1883). The true Christian religion (J. Chadwick, Trans.). London: The Swedenborg Society. (Original work published 1771)

Swedenborg, E. (1928). The Word of the Old Testament explained (A. Acton, Trans.). London: The Swedenborg Society. (Original work published 1746-1747)

Swedenborg, E. (1931). Heaven and hell (J. R. Rendell, Trans.). London: The Swedenborg Society. (Original work published 1758)

Swedenborg, E. (1986). Emanuel Swedenborg's Journal of Dreams (J.G.G. Wilkinson, Trans., commentary W. Van Dusen). New York: Swedenborg Foundation. (Original work published 1859 )

Swedenborg, E. (2006). Life on other planets (J. Chadwick, Trans.). London: The Swedenborg Society. (Original work published 1758)

Tafel, R. L. (1875a). Documents concerning the life and character of Emanuel Swedenborg (Vol. 1). London: The Swedenborg Society.

Tafel, R. L. (1875b). Documents concerning the life and character of Emanuel Swedenborg (Vol. 2, Part 1). London: The Swedenborg Society.

Terekhin, P. I. (1996). The role of hypocapnia in inducing altered states of consciousness. Human Physiology, 22, 730-735.

Tien, A. Y. (1991). Distributions of hallucinations in the population. Social Psychiatry and Psychiatric Epidemiology, 26, 287-292.

Toksvig, S. (1948). Emanuel Swedenborg: Scientist and mystic. London: Faber and Faber. 
Vaitl, D., Birbaumer, N., Gruzelier, J., Jamieson, G. A., Kotchoubey, B., \& Kubler, A., et al. (2005). Psychobiology of altered states of consciousness, Psychological Bulletin, $131,98-127$.

Van Dusen, W. (1972). The natural depth in man. New York: Harper \& Row.

van Lommel, P. (2004). About the continuity of our consciousness. Advances in Experimental Medicine and Biology, 550, 115-132.

van Lommel, P., van Wees, R., Meyers, V., \& Elfferich, I. (2001). Near-death experiences in survivors of cardiac arrest: A prospective study in the Netherlands. Lancet, 358, 2039-2045.

Watkins, J. (2008). Unshrinking psychosis. Paper presented at the meeting of the International Recovery from Psychosis Conference, Perth, Australia.

Whinnery, J. E. (1997). Psychophysiologic correlates of unconsciousness and near-death experiences. Journal of Near-Death Studies, 15, 231-258.

White, W. (1867). Emanuel Swedenborg: His life and writings. London: Simpkin, Marshall.

Yonelinas, A. P., Kroll, N. E. A., Quamme, J. R., Lazzara, M. M., Sauve, M. J., \& Widaman, K. F., et al. (2002). Effects of extensive temporal lobe damage or mild hypoxia on recollection and familiarity. Nature Neuroscience, 5, 1236-1241.

Zornberg, G. L., Buka, S. L., \& Tsuang, M. T. (2000). Hypoxic-ischemia-related fetal/ neonatal complications and risk of schizophrenia and other nonaffective psychoses: $A$ 19-year longitudinal study. American Journal of Psychiatry, 157, 196-202. 